\title{
Celebrating the Fiftieth Anniversary of the Association for Women in Psychology: A Life in Feminist Psychology: A Long and Interesting Journey from Ft. Wayne to Newport (Herstory)
}

\author{
Laura S. Brown ${ }^{1}$ \\ Published online: 28 March 2019 \\ (C) Springer Science+Business Media, LLC, part of Springer Nature 2019
}

\begin{abstract}
The present commentary addresses the radical history of feminist psychology and the Association for Women in Psychology. In it, I explore innovations with roots in feminist psychology that have been adapted and co-opted by mainstream psychology, and I propose some future directions for deconstructing feminist psychology's remaining allegiances to the dominant cultures of academic psychology and psychotherapy.
\end{abstract}

Keywords Feminist psychology $\cdot$ Feminist therapy $\cdot$ Liberatory psychology $\cdot$ Social justice

In my second month as a graduate student in clinical psychology, at which point I had only been driving for 3 months, I got into my trusty used Plymouth Duster and set out on my first foray onto an interstate highway. Remember, this is long before GPS or map apps; what is impressive is that I killed no one on the way as I tried to drive and pay attention to road signs simultaneously. I had never driven that far, but the perils of navigating the 388 miles from Carbondale, IL to Ft. Wayne, IN paled in comparison to what waited for me there. I was in love. The woman who was the recipient of that love was coming from Cleveland, where I had been living before grad school, to a conference in Ft. Wayne, and it was a place I could legitimately be in my continuing pursuit of her. The conference was secondary as a motivation for my trip - but the conference, and the organization sponsoring it, turned out to be the relationship that lasted. It was the first Association for Women in Psychology (AWP) conference.

Love got me to the first AWP conference. Although I was already a member, thanks to said object of my affection, and had defined myself as a feminist psychologist in the year before I headed to my graduate studies in Carbondale, I would likely never have gone to the conference were it not for that

Laura S. Brown

laurabrownphd@gmail.com

1 Independent Practice, $41311^{\text {st }}$ Ave NW, Seattle, WA 98107, USA woman I was pursuing. I did not have the money for the trip, and I was terrified of being on the highway. If I had not gone to Ft. Wayne, I would likely have made it to a conference somewhere along the line, and then my life would not have been set on its trajectory.

Because I was in love, I had the revolutionary experience of being there that weekend, not quite at the creation of AWP, but damn close. I was 20 years-old, energetic, and fresh off an undergraduate career as a political organizer. To my amazement and delight, no one at AWP that weekend asked me how old I was or whether I had any experience doing the things that I raised my hand to volunteer for-like putting on the second AWP conference back in Carbondale with a motley band of other feminist psychology graduate students a year and a half later.

I am not sure that anyone born after that year (1973) appreciates how utterly radical it was for the "grownups" in the room, who must have been all of their mid-30s, or maybe 40-years-old at best, to take seriously a youngster with a Jewfro out to here, braless in her overalls with her dyke button pinned to the bib, and looking the antithesis of professional. At least the grownups all had their doctorates! In a world where hierarchy prevailed, where young women existed (when we were allowed in the room at all) mainly to be eye candy or worse for predatory male professors, where you had to be connected to get in on the action, AWP's position of radical inclusion and non-hierarchical and egalitarian leadership was the first of many such powerful departures from 
professional life as usual that I had the privilege to encounter at the conference.

In 1973 it was an impressively radical thing that AWP did by embracing and empowering students and early career professionals decades before it became fashionable to do so in mainstream psychology. If you could do the work, then you could chair a committee or be the Harrier, the position we now call the CoCo [i.e., the lead facilitator of the organization]. I raised my hand and did all of that before I had my $\mathrm{PhD}$ in hand. You could be authoritative and no one checked your credentials; you got credibility by behaving competentlyperiod. AWP insisted on collective decision-making, on making all voices equal, and on spending the time to ensure that those voices were all heard, even when that led to marathon business meetings.

Who do I recall being in the room at that first conferencewho were the voices that woke me up and welcomed me? Barbara Wallston of "empowering memory" [a term I use in preference to the common "of blessed memory" to note both the secular nature of my memorial tribute as well as the empowering nature of a person who has died] was in the room at that conference, and she impressed me with her erudition and sense of humor. Barbara was later to be one of the first "psychology of women" leaders to say that we needed to call this thing of ours "feminist psychology" because simply looking at women without a feminist lens did not advance our goals. JoAnn Evans Gardner of empowering memorywho had been pushed out of academic psychology by misogyny, had turned into a powerhouse of feminist organizing and early feminist psychology publishing, and who showed up at the conference with a copy machine so that we could generate manifestos and immediately get them out-was there. Itene Frieze (1976) was at the conference where she shared her research on gender and attributions for success, research which has led to decades of feminist psychologists wishing one another "good skill" rather than "good luck."

Adrienne Smith of empowering memory comfortably walked around in the student union building where the conference was being held being an openly lesbian psychologist who seemed all calm about that openness. This was 1973; most of the queer people in psychology were in deep welldefended closets. But not Adrienne, who was there with her partner in practice and writing, Ruth Siegal of empowering memory, who was the embodiment of a straight ally. Adrienne's comfort with being visible as a lesbian in psychology was especially huge for me because the girlfriend I had driven to Ft. Wayne to see, who was just then finishing her doctorate and on whose dissertation research I had worked as a courtship strategy, was terrified that if anyone ever knew about us (really, about her), that her life and career would be over. Against my own judgment, I had followed her lead into the closet when I started my doctoral program; 2 months later when I came home from Ft. Wayne to Carbondale I promptly reversed course and came out to everyone, because Adrienne had shown me that this was possible.

Arnie Kahn, who was the first man I knew in feminist psychology and who went on to become a mentor for several generations of feminist psychologists, was in that room. Rhoda Kessler Unger, who was even then deconstructing gender and power as well as making clear that power was not essentially inherent in being assigned male at birth, attended. Jacqueline Macaulay, who had been nepotism-ruled out of her academic career but was nonetheless a visible and potent contributor to the earliest literature on sexism's effects on women's well-being, modeled for me that one could be a scholarly contributor even outside the academy. Kathy Grady, who I last caught sight of decades ago during a political war in mainstream psychology, was very much in the room and in the business meetings. Kathy modeled the importance of feminist process for getting where we were trying to go and insured that everyone had a voice in the room (and that AWP got itself some bylaws because a little structure was not a bad thing). Cathryn Adamsky, who was at that time on faculty somewhere in the general vicinity of Ft. Wayne, pulled that conference together. Who else was there that weekend I am not sure. I met so many powerful feminist psychologists via AWP in the subsequent years - Hannah Lerman, Lenore Walker, Nancy Felipe Russo, to name a few of my many mentors - that I do not quite trust my memory of who else was in the room, or at the party that night at the home of a member of the Ft. Wayne Feminists, or putting most of us up and starting the fine tradition of trying to make AWP accessible to broke grad students and early career professionals.

It is the profoundly radical nature of AWP, as well as the revolutionary discipline of feminist psychology that it nurtured and sustained, which have framed my thoughts for this talk. I want to inspire us by looking back at how much we have changed psychology - its science, its practice, and its pedagogy. It is that radical and consistent vision of how feminist activism could transform psychology that has allowed me, and thousands of other people since then, to claim our own versions of that radical vision, to write them down, to put them into action, and to collectively create our field.

It was not simply a matter of raised consciousness that I got from AWP. By the time I went to Ft. Wayne, I already knew that much was rotten in the field of psychology. I had read Women and madness (Chesler 1972); in fact our little women's center at Case Western Reserve University had brought Phyllis Chesler to Cleveland for a lecture at which the local psychiatrists and psychologists in attendance sat stone-faced among the feminists while Chesler told the truth about the misogyny of psychotherapy. Because my beloved's dissertation research was a replication of Broverman et al.'s (1972) study with a different participant group, I had not only read the original article but also scored hundreds of answer sheets that used all of the original prompts from that study. I 
had stumbled into Weisstein's (1970) "Kinder, Kuche, Kirche" when I brought home a copy of Sisterhood is Powerful (Morgan 1970).

So, I had had my consciousness raised about problems in psychology. Sexism was real, and the field into which I had been pointing myself since the age of nine was rife with it. Had my consciousness raising group (which was populated by feminist psychologists, psychiatrists, social workers, and psychiatric survivors) not pushed me to keep heading toward grad school, I would have given up on psychology entirely in the year that I worked inpatient psych, saw the misogyny at work, and often felt discouraged about my professional goals.

But AWP, along with the feminist psychology and activism that it nurtured, got me past simple awareness. AWP also gave me hope. On the day I left for Ft. Wayne, I had yet to appreciate just how radical feminist psychology - and AWP as a prime example of that discipline - were and would be. Other social scientists and psychotherapists had levied critiques against the dominant cultures of academic psychology and psychotherapy practice. For example, the community psychology movement and the family therapy world challenged psychology's individualistic focus; the progressives of the Society for the Psychological Study of Social Issues questioned taking research funding from the militaryindustrial complex and studied authoritarianism. But as far as I can tell from today's vantage point, none of those previous protest movements in psychology has ever gone as far as we did in AWP and feminist psychology. None of them had been so committed to walking their talk that they blew up all semblance of hierarchy in how the organization was run. None of them kept on challenging the norms and messing with the rules by creating new science, new practice, and new ethics. But feminist psychology has done so.

What AWP and feminist psychology proceeded to do was not simply critique what was wrong with the status quo. Feminist psychology has created an entirely new set of assumptive paradigms, new epistemologies, new language, and new standpoints. I would like to walk us through a few of those radical contributions and insights that were so wise that, as the decades have gone by, the rest of our fields have adopted and coopted them. I want to go back 5 decades and examine those potent seeds of change planted by the brave women and men who founded and nurtured AWP through its early years. The subversive modalities that grew from this soil of radical feminism have been domesticated within mainstream psychology to the point where their roots in feminist psychology and AWP have become obscured. I want to discuss what I have seen as the radical capacity of intersectional feminist psychology to transform and subvert many different dominant paradigms.

I also want to talk about some new ideas I have about what we might have been missing and what we might consider opening ourselves up to. Interestingly, some of these even more radical directions did emerge in those early days of feminist psychology, and they got pushed to the side because all of us, no matter how radical, were still trying to get jobs or degrees or tenure within the system as it was. There was so much risk inherent in being interested in feminist issues in psychology that we sometimes bent ourselves into pretzels trying to show that we were also playing by the rules - that is, by the logical-positivist research model and by the individual, pathology-informed psychotherapy model.

What are some of those revolutionary proposals that came out of AWP and feminist psychology in general? How about doing research on people who were not White men before opining about humans in general? In the psychology that I learned on the way to my $\mathrm{PhD}$, not only was even the rat white, but it was also cisgender male, heterosexual, likely middle-class, and a sophomore in a Midwestern land-grant university who was in the mandatory "subject pool" in his Introductory Psychology course-where he learned more about operant conditioning than about gender by a factor of approximately infinity. Feminist psychology started out looking at women's lives because almost no psychologist had done so, even when writing about women. As Weisstein (1970) pointed out, our lives were extrapolated from those of female rats and non-human primates.

This understanding does not seem particularly radical today. We are intersectional feminists; we look at an entire multi-strand weaving of people's identities and experiences. But I cannot over-emphasize how revolutionary, and how dangerous to the careers of all involved, it was to study women and gender roles on purpose, out loud, and (even more radically) through a feminist lens. AWP provided much important support for those people and their work. The annual conference was one such foundational component - a place to present findings that were unwelcome elsewhere, to be in the presence of colleagues who were equally pioneering, and to share data and ideas. You could have conversations at AWP that were honest and political and that would not come back to bite you. The Distinguished Publication Award was generated, despite AWP's anti-hierarchical stance, because we thought that if we recognized the best of feminist psychological work that it might help winners' careers along - and it certainly did that for me, a non-academic independent scholar who simply could not avoid putting down her thoughts on paper. [Notably, at the 2019 AWP conference, the 2018 Distinguished Publication Award session was led by Emily Keener and Clare Mehta (issue editors, 2017) for their special issues, Honoring feminist scholar Sandra Bem, Parts $1 \& 2$, that were published in Sex Roles, and the 2018 Lesbian Unpublished Manuscript Award talk was given by Chmielewski 2017 for her paper that subsequently was published in Sex Roles.]

I cannot count the number of people I met in the first decade of AWP who were in the middle of, or had just lost, a tenure fight in which their daring to publish on anything 
related to women and gender had been used to demean and devalue a stellar publications record. This seemed especially true for research on gendered violence, a topic entirely invented by feminists in psychology and the related disciplines. This research was explosive. It was denigrated. As a tenure committee member said to one of my friends back then, "Your research on rape and its effects [which was published in the Journal of Personality and Social Psychology] is correlational, not experimental." Her university denied her tenure while giving it to a peer with half her publications record and none of her mentoring of graduate students. As important to the tenure decision as his gender was his entirely mainstream, non-provocative research on group dynamics, in which "subjects" (as they were then called) were randomly assigned to different conditions, and thus was appropriately experimental in logical positivist terms. Here is the truth about studying violence and discrimination and the realities of the lives of marginalized people: You cannot study rape — or intimate partner violence, or sexual harassment, or microaggressions or the effects of any form of systemic oppression - by randomly assigning people to conditions of rape/not-rape or exposure to oppression or not.

As feminist psychologists, we knew that we had to study these previously hidden and forbidden topics and that we had to do so from the experiences of survivors and through a feminist lens: No more "masochism of the wife-beater's wife"; no more "seductive children." Feminist research on intimate violence blew the cover off the lies about who was raped, who was beaten, and who was sexually harassed or abused. The revolutionary courage of that first generation of feminist psychological scientists who were willing to risk it all is easy to forget today when there are specialty journals published by Sage, Oxford University Press, Springer, and the American Psychological Association (APA) on violence against women and the psychology of racism. Some of the editors of those journals were among that early cohort of courageous feminist psychological scientists whose careers had a less straightforward trajectory because they had to bob and weave around the objections of the this-isn't-science narrative. Feminist psychological scientists had to invent and then hone the qualitative methodologies that were, in 1973, not even treated as legitimate approaches to research. We had to have Sue Morrow of empowering memory demonstrate that highquality feminist qualitative research could beat out logical positivist empiricism when the truth about the experiences of survivors was at stake.

In a day and age in 2019 where doing work on violence can get you promoted to full professor in quite a few psychology departments rather than dumped into the limbo of being nontenure track or a research associate, it can be more difficult to recall that speaking truth to power led to derailed trajectories of professional development for many brilliant scholars. Women's Studies programs in particular benefited from the presence of feminist psychologists who had been exiled from psychology because they had dared to research the truths of our lives.

And then there is the visibility and empowerment of lesbians in psychology, a topic quite understandably close to my heart. The women's movement in general had not made its mind up quite yet about lesbians in the early 1970s. Homophobia was rampant in psychology departments; lesbians and gay men of the generations older than mine were firmly in the closet and did not always appreciate folks like myself who proclaimed our identities (e.g., see under that dyke button on my overalls). In contrast, AWP and its largely non-lesbian membership welcomed lesbian presence, empowered lesbian leadership, and supported high-quality and non-pathologizing research on lesbians' lives. They were allies and mentors and protectors. My first ever professional conference presentation happened at AWP conference \#2 in Carbondale, IL where I shared my Master's thesis research that compared and contrasted the response of lesbians and matched heterosexual controls on a variety of measures of psychological well-being, finding no statistically significant differences between the two very large groups of research participants. The presentation sparked an in-depth discussion among those present about the political and social utility of keeping lesbians stigmatized and pathologized, a conversation that moved me and many of those present past the state of research as it was (i.e., "Look, we're just like you") to more lesbian-centered, lesbian-affirmative work that celebrated the strengths inherent in our outsider status.

That presentation happened to have occurred in the presence of a woman, Florence Denmark who was, without my knowing so at the time, one of the most powerful feminists in the world of mainstream psychology and on her way to the presidency of APA a few years later. Florence began to mentor me that weekend; she became my powerful heterosexual ally, encouraging and protecting me from homophobia among my professors. There were a lot of those allies for lesbians in the leadership of AWP; some of them, like Anne Peplau, did research on lesbian issues, risking being labeled lesbian at a time when that did not do good things for one's career. Some of them, like Florence and Nancy Felipe Russo [the director of APA's Women's Programs Office] used their power to advance lesbians' careers and visibility. I can recall a period in the mid-1980s when one or the other of them was calling me regularly because a lesbian presence was needed at such and so a psychology event. Being a token then was acceptable because our allies were carving out seats for us at the table. That ally-ship had its roots in AWP.

At a time in 2019 when the second openly lesbian president of the APA [Sandra Shullman] has just been elected, more than two decades after Bonnie Strickland pioneered lesbian visibility at the highest levels of psychology, and in a moment in time when queer visibility of all kinds seems ubiquitous in 
some corners of our field, it is again difficult to grasp the revolutionary acts inherent in AWP where heterosexual feminist psychologists embraced lesbians, were our allies, and promoted our research - more than a decade before there was a Division 44 [Society for the Psychology of Sexual Orientation and Gender Diversity: https://www.apa.org/ about/division/div44] and years before the Association of Gay Psychologists gave in to lesbian pressure and added "Lesbian" to their name. For lesbian feminists in psychology, AWP was our home. And, do not overlook AWP's dance where all the women dance together, flouting heterosexist and homophobic norms about women flirting with women on the dance floor. AWP created lesbian safer spaces that made it possible to venture out into the still-hostile world of mainstream psychology where a majority of clinical psychologists still endorsed the notion that LGBTQ people were inherently pathological.

Turning back to some more academic topics, there is masked review of journal article submissions. The founding members of AWP, and those in positions of greatest visibility for the first decade at least, were primarily social, developmental, and experimental psychologists. Many of them were assistant professors; they needed publications in order to get tenure. But how to get published when, as some of their research demonstrated, likely better-recognized senior male psychologists were significantly more likely to be published than similarly senior women (Guyer and Fidell 1973)?

AWP members took the lead within psychology in lobbying for masked review. It is a norm today; I have been on the editorial boards of a score of journals, only two of them feminist-Psychology of Women Quarterly and Women and Therapy - and every single one of those journals has masked review. This is not to say that after a time an editorial reviewer can begin to recognize familiar writing styles and the long lists of citations to self that have been redacted for the sake of masking (Ceci and Peters 1984); rather, that as a result of feminist psychology's persistent activism, the ethics of masked review have become more enshrined in scientific psychology. That has meant that work was published because of its merit and the soundness of its science and analysis, not because the name of the first author suggested being assigned male at birth.

Intersectional feminisms were a thing in AWP well before Crenshaw (1991) coined the term we all use today. I would like to claim that this is a radical construct that emerged from the work of feminist psychology. This is because in 1981 at the AWP conference in Boston, Oliva Espin, occupying the keynote position for the conference, gave a rousing call to awareness about the whiteness and mono-cultural nature of AWP as it was then. There was a great awakening that continued through the 1980s both in AWP and in other corners of feminist psychology. The next AWP conference, held in Seattle in 1983 and put on by a merry band of intersectional feminists with yours truly running the meetings, determined that we would set a standard in which presenters had to address all aspects of women's identities, not simply their femaleness. In 1985, the Feminist Therapy Institute (FTI), which had spun out of AWP in 1982, began similar efforts to address racism, classism, heterosexism, anti-Semitism, ageism, and ableism in the practice of feminist therapy as a strategy toward encountering women in the fullness of their intersectionalities.

The books, Diversity and Complexity in Feminist Therapy (Brown and Root 1990) which emerged from the FTI's 1988 Seattle conference, and Racism in the Lives of Girls and Women (Adleman and Enguídanos 1995), a project that grew from FTI's 1989 meeting in Calgary, were the initial feminist scholarship exploring the meanings of intersectionalities. Maria Root, who co-edited the Diversity and Complexity book, proposed her ecological theory of mixed-heritage identity development in which she elegantly accounted for the multiplicity of trajectories possible in intersectional identity development (Root 1990). Before Crenshaw (1991), and long before being an intersectional feminist was a norm (Shields 2008), feminist psychological scientists and psychotherapists in AWP and FTI were already showing the way toward our embrace of this now-foundational paradigm.

Informed consent in psychotherapy is mandatory today, with some jurisdictions enshrining it into law. But when Hare-Mustin et al. (1979) published "Rights of Clients, Responsibilities of Therapists," calling for all therapy to be preceded by full informed consent, the ruckus in the notfeminist psychotherapy world was exceedingly loud and indignant: "We couldn't do that! Our clients would sue us!" Therapy was a mysterious relationship, not a contracted fiduciary thing. The notion that clients should have informationabout the therapist's training, about what to expect, about the rules that said that your therapist should never have sex with you, about the allegedly neutral transferential screen - these all turn out to be what are now considered best practices. But all of this was explosively radical then.

Empowering clients to imagine themselves as consumers with rights was considered to be so radical as to leave many non-feminist therapists unsure of whether what we feminists were up to still deserved to be called psychology. I had my own brush with that feminist-psychology-is-not-real-psychology narrative when I went for my ABPP [American Board of Professional Psychology] diplomate in 1985. Despite the fact that the material in that work sample went on to win the Distinguished Publication Award from AWP on the topic of women and trauma (Brown 1986) as well as a second article from that work sample on gender in psychological assessment being published in Professional Psychology (Brown 1990), not precisely a feminist journal, I had my examining committee tell me that I was a fine feminist therapist, but that feminist therapy was not a part of clinical psychology. 
Psychiatric diagnosis is another area where feminist psychology asked radical questions - and in many ways is still asking them. Paula Caplan, Hannah Lerman, Mary Ballou, and the whimsically named "Coalition Against Ms.Diagnosis" all took the lead on challenging misogyny as enshrined in the formal diagnostic manuals - and in a few cases, won. Feminist psychologists led the way on asking, and continuing to ask, the inconvenient questions about the value, nature, and use of psychiatric diagnosis well before mainstream social commentators began to notice that there might be something amiss with the so-called "bible" of psychiatry [the Diagnostic and Statistical Manual of the American Psychiatric Association]. In concert with feminist psychologists like Lynne Bravo Rosewater and Mary Anne Dutton, who were deconstructing and critiquing those old saws of diagnosis, the MMPI [Minnesota Multiphasic Personality Inventory], and Millon inventories (https://www. pearsonclinical.com/psychology/products/100000509/ millon-inventories.html\#tab-details), diagnosis critics like Caplan (1995) were taking the radical step of asking whether it was safe to use such instruments or apply diagnostic labels derived from them.

Today, at least in some educational settings, graduate students are exposed to critical thinking about diagnosis and assessment by being invited to ask questions and with particular focus on the mono-cultural nature of the entire taxonomic endeavor. But please do not forget that in 1986 when the American Psychiatric Association attempted to put the diagnoses of Self-Defeating Personality Disorder (otherwise known as complex trauma due to continuous abuse) and Paraphilic Rapism (i.e., he has an uncontrollable urge to rape and is not a criminal, but rather is mentally ill) into the DSM $I I I-R$, it was feminist psychologists and psychiatrists, AWP, and FTI who were out on the sidewalks of Washington, DC in suits, hose, heels, and picket signs.

And then we have the matter of representation. When I started grad school, women represented less than $20 \%$ of new doctorates in the discipline across all sub-specialties. Today we represent the bulk of degrees in clinical and counseling psychology as well as healthy numbers of new doctorates in scientific psychology (https://www.apa.org/pi/ women/committee/wapa-2006.pdf). Selecting applicants to graduate programs based on their merit and not their gender, including adequate representation of women and other marginalized groups on the editorial boards of journals and on APA governance groups has changed the face of psychology indelibly.

Or have we? Forty years ago in her 1979 commencement address at Smith College, the farseeing poet and prophet Rich (1986) spoke of the seductions inherent in dominant culture and its institutions for highly educated, capable women. It was easy, she pointed out, to become a token and to swallow the narrative of exceptionalism; to think of yourself as so much better than all of the other women so that you, but not they, deserved this tiny niche; and to believe that your exceptionalism was a privilege protected by excluding other women from whatever club into which you had been allowed. That belief system protected you against knowing that misogyny was systemic and profound, she noted. When equality of opportunity becomes mandated, as it did for all APA-accredited programs in 1972, numbers changed. Attitudes, however, did not, and the phenomena of identification with the oppressor and horizontal hostility have not been lessened by the greater numbers of female-identified people in the psychological academy or in psychotherapy offices. It turns out that it is often easier to get female-identified bodies with no feminist identities into places of power and privilege than it still is to get feminists of any variety into those same seats.

Women are a majority within psychology today; selfidentified feminists, not so much. It matters that past APA presidents Florence Denmark, Bonnie Strickland, Norine Johnson, Diane Halpern, Dorothy Cantor, Melba Vasquez, Carol Goodheart, and Jessica Henderson Daniel are selfidentified feminists (as are current President Rosie Phillips Bingham-Davis and President-Elect Sandra Shullman) and that Florence, Norine, Melba and Jessica all had been president of APA's Division 35 [Society for the Psychology of Women], AWP's sister organization, before being presidents of APA. It matters that not all of the female-identified presidents of APA were identified as feminists; it speaks to how the token phenomenon turned out to be an unintended consequence of our collective push for representation. Psychology has more women in leadership today than at any time in its history. It has more feminists than before as well, but the part of the Venn diagram where that overlaps with women in leadership only looks like 50\%. The irony of the success of feminism within psychology is that women are well-represented, but a feminist perspective continues to be marginal.

This understanding is a small part of why AWP - as a radical intersectional feminist organization existing separate and apart from APA, Division 35, the APA Women's Programs Office, Division 17's [Counseling Psychology] Section for the Advancement of Women, in other words, standing at the side of all of our feminist sisters within organized psychology - remains relevant and necessary. AWP owes allegiance only to feminist principles, not to organized psychology. AWP need not compromise to fit in. We are, consequently, no longer in the business of simply getting femaleidentified bodies in the room. That was a starting point - and not a bad one. But I think we are mostly out of that business of simply counting the female-identified bodies in the room.

Instead, we are in the still-radical business of challenging the design and layout of that room, the politics of its power dynamics, and the assumptive foundations of its knowledge 
claims. As Lorde (1984) said, "the master's tools will never dismantle the master's house" - and remodeling that house turns out not to suffice for the goals of radical feminist psychology. AWP did not start simply to have more women in psychology; it started with the goal of dismantling structural hierarchies of oppression within the field that were in part exemplified by the exclusion of women's bodies, women's vision, women's voices, and women's presence-along with so many other forms of exclusion. Those structural hierarchies are still in place for the most part. They have been prettied up a bit by the cooptation of feminist ideas, but they are as much there today in 2019 as they were in 1969, the year I started my undergraduate career. We here in feminist psychology are still doing the subversive work of asking difficult questions and of upending assumptions about how knowledge is generated, by and with whom, and for what purpose.

So let me end by asking a few more subversive and radical questions myself. During the last 2 years I have been working on a new book; progress got a little interrupted in January when I got a cancer diagnosis and had to spend time having tests and surgery and follow-up appointments instead of going on a writing retreat. (I am going to be fine, stage 1B melanoma, just something I'll have to be on the lookout for forever.) But my point is that I have been thinking a lot about what we-as social justice psychologists, as intersectional feminists, and as people raised in, and intellectually colonized by, the cultures of psychology as it has pretty much always been-might have missed or might even have chosen to look away from because we assessed that the times were not yet right to expose the fullness of the revelations we had. We are all thoroughly colonized members of our lay and professional cultures; we may, and we often do, balk at the mental chains on our metaphoric shoulders. But we live in a white supremacist capitalist patriarchy - each and every one of us, no matter where we are on the planet. The hegemony of U.S. culture and its colonization of the discipline of psychology globally means that no one escapes the epistemic reach of these oppressive structures. We must have a job to survive and to pay for healthcare and childcare and the education of our young, although in some places in the world this is slightly less of a struggle, and in others, much more of a struggle. We live at the mercy of the $1 \%$ who create and destroy workplaces all over the planet like so many large, careless children; thus, few of us are secure.

So we make bargains with ourselves - and feminist and other liberatory psychologies have made bargains in order to continue to exist within the confines of our disciplines. What I want to throw out here are a few of the radical ideas that I have been dancing with inside my head over the last couple of years about the practice of psychotherapy (for example, see Brown 1994, 2018). I do not have quite as many good ideas about research because that is not what I have mostly done with my time; instead, ask Michelle Fine, who has gorgeous and thoroughly radical ideas about decolonizing and developing participatory action research (Cammarota and Fine 2008).

These are ideas that very much have their roots in the feminist psychology that AWP has nurtured. They also in many ways reflect where I am in my career: 66-years-old, retired from psychotherapy practice, no longer in a position where I am dealing with insurance companies or Medicare [federally funded U.S. healthcare for people over 65 or living with disability] _ in short, in a position of some privilege. I am in a position of finally not needing to make a living, of not worrying how medical bills will be paid (unless, of course, Medicare is abolished). I am in the position of the crone, which is one of power and the privilege to speak more truths out loud. To quote Sontag (1973), writing almost 50 years ago:

The first responsibility of the liberated woman is to lead the fullest, freest, and most imaginative life she can. The second responsibility is her solidarity with other women...she has no right to represent her situation as simply or less suspect or less full of compromises that it really is (1973, p. 206).

In attempting to generate that fullest, freest, and most imaginative life for all, it is worth telling the truth about the complexities, the betrayals, and the compromises that we have been making in feminist therapy while trying to bridge the gap between the radical truths we know and the practical realities of financial and professional survival. A few radical propositions, then, to end my talk-propositions that I hope someone will catch and develop more thoroughly in precisely the way I caught the radical ideas being tossed into the air in Ft. Wayne. Some of my thoughts follow.

Rogers (1995, p. 318), in A Shining Affliction, which is her memoir of betrayal in psychotherapy, wrote: "If we consider carefully the possibility that an individual's failed psychotherapy may center around a systemic corruption of a relationship that should be basically trustworthy, then our current practice of psychotherapy becomes suspect, or open to questions." Our entire current practice-including the practices of intersectional feminists, womanist, psychotherapy-is suspect and needs to be questioned. We have been corrupted, but so much from our inception that this corruption is nearly invisible.

What is the systemic corruption that strips the trust from relationships that ought to be basically trustworthy? What is inherently corrupt in all of our enterprises? Why do we conduct our work as we do? Feminist psychotherapists have a 45 to 50-min psychotherapy non-hour sessions because that is what the psychoanalysts who were all of our forbearers did - and because it then was institutionalized by the codes promulgated by the American Medical Association, known as CPT (Current Procedural Terminology) by which we are paid 
by insurance companies. To get paid for practicing psychotherapy in the U.S. one must submit the correct CTP code. Feminist therapists thus practice as colonized entities.

We maintain certain kinds of boundaries because that is what the psychotherapists before us did, except for the ones back in the 1960s who did not and then caused scandals that led us all to tighten things up even more. I am not sure that feminist therapy ever got over the wound caused by several powerful feminist therapy leaders of the 1970s making the decision to make their groups of trainees and clients also their stable of prospective sexual partners. I testified in lawsuits brought against several of these charismatic women who claimed that feminist principles of egalitarianism gave them the right to sexually exploit their clients. So feminist therapy as a discipline cleaned up its act. Feminist therapy tightened itself up well and thoroughly in the aftermath of those painful debacles. We double-colonized ourselves; those offenders were themselves colonized by white supremacist patriarchal ownership thinking - "These are my people, I can do with them as I wish." Then feminist therapy as a field colonized ourselves with fear-fear that dominant psychology culture would mistake our rumbling about misogyny in psychotherapy for the kind of damning betrayals that these several charismatic leaders and teachers perpetrated - fear that led us to be ever so focused on being sure that we did no harm, which meant, of course, that we took all of our wild and creative methodologies and put them carefully underground so that we would not be ejected from the temple of third-party payments and licenses.

No matter how many papers some of us write about why the language we use creates the realities we share, most of us in the world of feminist therapy call our feelings about the people we work with by a slave name, "countertransference," and we problematize and mystify those feelings. We diagnose people with terms that we know are socially constructed fictions because that is what the psychotherapists before us did and now also because we have to prove "medical necessity" to an insurance company if we want to get paid for what we do. Notice the dead hand of capitalist patriarchy sitting heavily on what we do, that is, on these decisions we make to remain colonized by the norms of the white supremacist heteropatriarchal hierarchies that we tell ourselves we are disrupting in our offices.

We do not disclose much about who we are or the reality that we are another suffering human being. Feminist therapy says yes, use self-disclosure; our colonized fears of how we will be perceived if we allow ourselves to become what Kravetz (1978) called, in the early years of our radical work, a "consciousness-raising group of two," have become more powerful than our radical insights that women speaking truth to one another can heal both. If we are individual psychotherapists, which means most of us, we never speak to the family, friends, co-workers, antagonists, or neighbors of the people we treat. Instead we get a carefully curated slice of their reality that, unless it sounds really atypical in some way (e.g., "I am seeing flying unicorns"), we accept as close enough to accurate. We have left in the dust the radical notions promulgated by some of our earliest thinkers that in order to engender healing from the wounds of patriarchy and white supremacy we must be fully participatory in the contexts of the lives of the suffering people with whom we work. We wrote that feminist therapy was best done in groups, but almost no feminist therapy groups appear to be found.

I could go on in my talk, but instead I am developing a book with the goal of blowing up the social justice therapies of today, just as 50 years ago feminist psychologists blew up the liberal humanist psychotherapists of the 1960s. All of which is to say that the radical notions that emerge from feminist psychology and from AWP have only begun to be developed and comprehended. We have transformed the field of psychology so much, on so many variables and yet from a distance, that it can be difficult to see what changes we have in fact made. But, our radical potential is almost entirely untapped.

We live today in the age of electronic miracles. I can learn what you are doing in far-away places by going online; we may never meet face-to-face. The disruption of the Cartesian mind-body split, much of it occurring at the location of understanding trauma (particularly chronic intimate violence), is making it impossible to parse humans and our behaviors in old ways. In the midst of the hegemony of CBT (cognitive behavioral therapies) and the evidence-based, creative new paradigms for healing distress, paradigms reflecting the new knowledge that we are truly biopsychosocialexistential creatures are courageously emerging. Furthermore, I can learn your new thing by going online to a webinar and participating that way-which, if I am a therapist whose mobility is challenged in some way, means that I am no longer excluded from the learning and the conversation.

Feminism is rethinking itself as our understandings of gender, sex, sexuality, and power are dissolved through the life experiences of those who are non-binary, who are transgender, and who are re-parsing sexual orientations to better reflect their lived experiences. These people are the actual and lived offspring of Le Guin's (1969) Left Hand of Darkness or Scott's (1995) Shadow Man, the visionary authors who took it seriously when we said that gender was just a social construct and that the body was only one way of knowing sex. We are living in a world where their work is no longer science fiction, but rather among the next revolutions to challenge feminist psychology and thus AWP.

I get annoyed, and then sad, that at age $66 \mathrm{I}$ am not going to be here in 50 years to experience those next radical transformations. I will write some more in the next few years about what I think should happen next in feminist, liberatory psychotherapy. I will finish one more book before I decide that enough is enough and spend more time with the guitar and 
less on the computer keyboard. But one of you reading my paper-someone who is looking for their dissertation topic or someone who just got their first academic job - is going to do with my pokes at white supremacist heteropatriarchy what my cohort and I were able to do with the pokes made by Barbara Wallston, E. Kitch Childs, and Hannah Lerman. I do not know who you are - only that you are sitting out there arguing with me in your head, excited by the thoughts I have evoked, and writing something down in your notes.

Hold on to that radical vision. Forgive yourself, and your elders, for the compromises that we have made and will continue to make as we uncover, layer after layer after painful layer, heteropatriarchal white supremacist colonization of our psyches and our ideas. Be as brave as you can tolerate. Never silence yourself.

And keep AWP going. Because as much today as 50 years ago, as much in another 50 years, the radical critique of white supremacists heteropatriarchal hierarchies in the science, practice, and teaching of psychology needs its home. Thank you AWP for having been that home for me, for being the place where I could say strange and provocative things out loud at little-to-no risk, and for having been the place where I met so many of my family of choice. Let us move on to foment revolution, because that way lies true knowledge of our species and true healing for those who have been wounded by systemic oppression.

Acknowledgments The present invited talk was delivered at the meeting of the Association for Women in Psychology in Newport, RI on March 1, 2019. The author wishes to thank Janice Yoder for her cogent editorial feedback, and Kat Quina and Jennifer J. Freyd for early readings of this paper.

\section{References}

Adleman, J., \& Enguídanos, G. (1995). Racism in the lives of girls and women. London: Routledge.

Broverman, I. K., Vogel, S. R., Broverman, D. M., Clarkson, F. E., \& Rosenkrantz, P. S. (1972). Sex-role stereotypes: A current appraisal. Journal of Social Issues, 28(2), 59-78. https://psycnet.apa.org/doi/ 10.1111/j.1540-4560.1972.tb00018.x.

Brown, L. S. (1986). From alienation to connection: Feminist therapy with post-traumatic stress disorder. Women \& Therapy, 5, 13-26.

Brown, L. S. (1990). Taking account of gender in the clinical assessment interview. Professional Psychology: Research and Practice, 21, 12 17.

Brown, L. S. (1994). Subversive dialogues: Theory in feminist therapy. New York: Basic Books.

Brown, L. S. (2018). Feminist therapy (2nd ed.). Washington, DC: American Psychological Association.

Brown, L. S., \& Root, M. P. P. (Eds.). (1990). Diversity and complexity in feminist therapy. New York: Haworth.
Cammarota, J., \& Fine, M. (Eds.). (2008). Revolutionizing education: Youth participatory action research in motion. New York: Routledge Publishers.

Caplan, P. (1995). They say you're crazy: How the world's most powerful psychiatrists decide who's normal. New York: Da Capo Press.

Ceci, S. J., \& Peters, D. (1984). How blind is blind review? American Psychologist, 39, 1491-1494. https://psycnet.apa.org/doi/10.1037/ 0003-066X.39.12.1491.

Chesler, P. (1972). Women and madness. New York: Doubleday.

Chmielewski, J. F. (2017). A listening guide analysis of lesbian and bisexual young women of color's experiences of sexual objectification. Sex Roles, 77, 533-549.

Crenshaw, K. (1991). Mapping the margins: Intersectionality, identity politics, and violence against women of color. Stanford Law Review, 43, 1241-1299.

Frieze, I. H. (1976). The role of information processing in making causal attributions for success and failure. In J. S. Carroll \& J. W. Payne (Eds.), Cognition and social behavior (pp. 95-112). Oxford: Lawrence Erlbaum.

Guyer, L., \& Fidell, L. (1973). Publications of men and women psychologists: Do women publish less? American Psychologist, 28, 157 160. https://psycnet.apa.org/doi/10.1037/h0034240.

Hare-Mustin, R., Marecek, J., Kaplan, A. G., \& Liss-Levinson, N. (1979). Rights of clients, responsibilities of therapists. American Psychologist, 34, 3-16. https://psycnet.apa.org/doi/10.1037/0003066X.34.1.3.

Keener, E., \& Mehta, C. M. (Eds.). (2017). The past, present, and future of masculinity, femininity, and gender: Honoring feminist scholar Sandra L. Bem (1944-2014), Parts 1 and 2. Sex Roles, 76(9/10 \& 11/12).

Kravetz, D. (1978). Consciousness raising groups in the 1970s. Psychology of Women Quarterly, 3, 168-186.

Le Guin, U. K. (1969). The left hand of darkness. New York: Penguin.

Lorde, A. (1984). The master's tools will never dismantle the master's house. Sister outsider: Essays and speeches (pp. 110-114). Berkeley: Crossing Press.

Morgan, R. (Ed.). (1970). Sisterhood is powerful: An anthology of writings from the women's liberation movement. New York: Random House.

Rich, A. (1986). What does a woman need to know. Blood, bread, and poetry: Selected prose 1979-1985 (pp. 1-10). New York: W. W. Norton \& Company.

Rogers, A. G. (1995). A shining affliction: A story of harm and healing in psychotherapy. New York: Penguin.

Root, M. P. P. (1990). Resolving "other" status: Identity development of biracial individuals. In L. S. Brown \& M. P. P. Root (Eds.), Diversity and complexity in feminist therapy (pp. 185-206). New York: Harrington Park Press.

Scott, M. (1995). Shadow man. Maple Shade: Lethe Press.

Shields, S. A. (2008). Gender: An intersectionality perspective. Sex Roles, 59, 301-311. https://doi.org/10.1007/s11199-008-9501-8.

Sontag, S. (1973). The third world of women. Partisan Review, 40, 180 206.

Weisstein, N. (1970). "Kinde, kuche, kirche" as scientific law: Psychology constructs the female. In R. Morgan (Ed.), Sisterhood is powerful (pp. 205-219). New York: Random House.

Publisher's Note Springer Nature remains neutral with regard to jurisdictional claims in published maps and institutional affiliations. 